\title{
Ventilator-induced lung injury is aggravated by antibiotic mediated microbiota depletion in mice
}

Sandra-Maria Wienhold ${ }^{1 \dagger}$, Mario Macri ${ }^{1,7 \dagger}$, Geraldine Nouailles ${ }^{1}$, Kristina Dietert ${ }^{2}$, Corinne Gurtner ${ }^{2,8}$, Achim D Gruber ${ }^{2}$, Markus M Heimesaat ${ }^{3}$, Jasmin Lienau ${ }^{1}$, Fabian Schumacher ${ }^{4,5}$, Burkhard Kleuser ${ }^{4}$, Bastian Opitz ${ }^{6}$, Norbert Suttorp ${ }^{6}$, Martin Witzenrath ${ }^{1,6^{*}+}$ and Holger C Müller-Redetzky ${ }^{1,6+}$

\begin{abstract}
Background: Antibiotic exposure alters the microbiota, which can impact the inflammatory immune responses. Critically ill patients frequently receive antibiotic treatment and are often subjected to mechanical ventilation, which may induce local and systemic inflammatory responses and development of ventilator-induced lung injury (VILI). The aim of this study was to investigate whether disruption of the microbiota by antibiotic therapy prior to mechanical ventilation affects pulmonary inflammatory responses and thereby the development of VILI.

Methods: Mice underwent 6-8 weeks of enteral antibiotic combination treatment until absence of cultivable bacteria in fecal samples was confirmed. Control mice were housed equally throughout this period. VILI was induced 3 days after completing the antibiotic treatment protocol, by high tidal volume (HTV) ventilation (34 ml/kg; positive endexpiratory pressure $=2 \mathrm{cmH}_{2} \mathrm{O}$ ) for $4 \mathrm{~h}$. Differences in lung function, oxygenation index, pulmonary vascular leakage, macroscopic assessment of lung injury, and leukocyte and lymphocyte differentiation were assessed. Control groups of mice ventilated with low tidal volume and non-ventilated mice were analyzed accordingly.

Results: Antibiotic-induced microbiota depletion prior to HTV ventilation led to aggravation of VILI, as shown by increased pulmonary permeability, increased oxygenation index, decreased pulmonary compliance, enhanced macroscopic lung injury, and increased cytokine/chemokine levels in lung homogenates.

Conclusions: Depletion of the microbiota by broad-spectrum antibiotics prior to HTV ventilation renders mice more susceptible to developing VILI, which could be clinically relevant for critically ill patients frequently receiving broad-spectrum antibiotics.
\end{abstract}

Keywords: Broad-spectrum antibiotic therapy, Ventilator-induced lung injury, Microbiota

\footnotetext{
* Correspondence: martin.witzenrath@charite.de

†Sandra-Maria Wienhold, Mario Macrì, Martin Witzenrath and Holger C

Müller-Redetzky contributed equally to this work.

${ }^{1}$ Division of Pulmonary Inflammation, Charité - Universitätsmedizin Berlin,

corporate member of Freie Universität Berlin, Humboldt-Universität zu Berlin,

and Berlin Institute of Health, Berlin, Germany

${ }^{6}$ Department of Infectious Diseases and Pulmonary Medicine, Charité -

Universitätsmedizin Berlin, corporate member of Freie Universität Berlin,

Humboldt-Universität zu Berlin, and Berlin Institute of Health, Charitéplatz 1,

10117 Berlin, Germany

Full list of author information is available at the end of the article
}

(c) The Author(s). 2018 Open Access This article is distributed under the terms of the Creative Commons Attribution 4.0 International License (http://creativecommons.org/licenses/by/4.0/), which permits unrestricted use, distribution, and reproduction in any medium, provided you give appropriate credit to the original author(s) and the source, provide a link to the Creative Commons license, and indicate if changes were made. The Creative Commons Public Domain Dedication waiver (http://creativecommons.org/publicdomain/zero/1.0/) applies to the data made available in this article, unless otherwise stated. 


\section{Background}

Mechanical ventilation (MV) is a live-saving intervention in acute respiratory failure. Patients in intensive care units (ICU) are often subjected to MV, which can induce local and systemic inflammatory responses, thereby leading to the development of ventilator-induced lung injury (VILI) [1, 2]. VILI contributes to mortality and morbidity in patients with respiratory failure $[1,3,4]$.

Critically ill patients in the ICU frequently receive antibiotics [5], and exposure to broad-spectrum antibiotics alters the microbiota. The microbiota is an "ecological community of commensal, symbiotic and pathogenic microorganisms" [6], which can be found e.g. in the gut, on the skin, and in the respiratory tract [7]. Recent studies revealed a significant impact of the physiological gut microbiota on the homeostasis of the immune system. The intestinal bacterial flora was shown to be essential for the calibration of local inflammatory responses of the gut [8]. Further, intact gut microbiota calibrates the systemic homeostasis between inflammatory and anti-inflammatory components and is essential for an effective immune response e.g. by altering IL-10 activity [9]. Recent studies suggest that the gut microbiota can also affect the pulmonary inflammatory response and associated lung injury [10-12]. For instance, lung inflammation, organ damage and mortality have been shown to be increased in antibiotic-treated mice infected with Streptococcus pneumoniae compared to controls, suggesting that the gut microbiota modulates local inflammatory responses in the lungs [13]. Translocation of commensal bacteria and their metabolites, including short-chain fatty acids, from the gut into the bloodstream was suggested as a potential underlying mechanism of the gut-lung interaction [1416]. Moreover, Clarke et al. revealed that components of the microbiota, after translocation from the gut into the bloodstream, also regulate the inflammatory activity of neutrophilic granulocytes [16]. This might be helpful for the host in the case of infection, but might be harmful within the context of autoimmunity or tissue trauma-induced inflammation caused by e.g. MV.

Currently, little is known about the effect of the microbiota on local stimulation of the immune system and pulmonary inflammatory phenotype in sterile lung inflammation. Although great effort is made to minimize antibiotic exposure in general, certain groups of patients are exposed to long and frequent antibiotic treatment. This includes patients that are rendered immunosuppressed by e.g. chemotherapy and that are often treated with antibiotics more frequently, for longer periods and under certain circumstances even for prophylaxis. Hence, by depleting the microbiota by antibiotic treatment prior to MV we examined the impact of the microbiota on the pulmonary inflammatory response to MV and thereby its influence on the development of VILI.
Some of the results presented here were previously reported in the form of abstracts [17-19].

\section{Methods \\ Animals}

Female C57BL/6N mice (Charles River, Sulzfeld, Germany) were used. Mice were housed under specific pathogen-free conditions with free access to food and water and $12 \mathrm{~h} \mathrm{light/dark}$ cycle. Animal housing and experimental procedures complied with the Federation of European Laboratory Animal Science Associations (FELASA) guidelines and recommendations for the care and use of laboratory animals.

\section{Generation of microbiota-depleted mice}

Long-term antimicrobial therapy was performed as previously described [20]. Briefly, 8-week-old mice were transferred to sterile cages and received a fivefold broadspectrum antibiotic cocktail (ampicillin $(1 \mathrm{~g} / \mathrm{l}$; Ratiopharm, Ulm, Germany), vancomycin (500 mg/l; Cell Pharm, Hannover, Germany), ciprofloxacin (200 mg/l; Bayer Vital, Leverkusen, Germany), imipenem (250 mg/l; MSD, Haar, Germany), and metronidazole (1 g/l; Fresenius, Bad Homburg, Germany)) via drinking water ad libitum for 68 weeks until the absence of cultivable bacteria in fecal samples was confirmed. Absence of cultivable bacteria in feces samples (applying thioglycolate enrichment broths; Oxoid, Wesel, Germany) for at least three consecutive weeks served as quality control for successful depletion of gut microbiota [20]. Applying the qPCR technique we observed that antibiotic therapy significantly depleted the commensal intestinal bacteria by 2-3 log levels compared to non-treated mice (Additional file 1: Figure S1). MV of depleted and control mice (ctrl) started $72 \mathrm{~h}$ after completing the antibiotic treatment protocol at the age of 14-15 weeks.

\section{Mechanical ventilation}

MV was performed as previously described [21]. Mice were anesthetized with intraperitoneal injections of fentanyl $(0.05 \mathrm{mg} / \mathrm{kg})$, midazolam $(5 \mathrm{mg} / \mathrm{kg})$, and medetomidine $(0.5 \mathrm{mg} / \mathrm{kg})$. Repetitively, fentanyl $(0.016 \mathrm{mg} / \mathrm{kg})$, midazolam $(1.6 \mathrm{mg} / \mathrm{kg})$, and medetomidine $(0.16 \mathrm{mg} / \mathrm{kg})$ were supplied via an intraperitoneal catheter, when required, to guarantee adequate anesthesia during the experiment. Body temperature was maintained at $37{ }^{\circ} \mathrm{C}$ by a body temperature-controlled heating pad. Mice were tracheotomized, intubated, and ventilated with tidal volume of $8 \mathrm{ml} / \mathrm{kg}$, respiratory rate of 160 per minute, fraction of inspiratory oxygen $\left(\mathrm{FiO}_{2}\right)$ of 0.5 and 2 $\mathrm{cmH}_{2} \mathrm{O}$ positive end-expiratory pressure (PEEP). A carotid artery catheter was applied for blood pressure monitoring and infusion of a balanced electrolyte solution (Jonosteril; Fresenius, Bad Homburg, Germany) 
containing $150 \mathrm{M}$ trometamol hydrochloride (B. Braun Melsungen AG, Melsungen, Germany) $(350 \mu \mathrm{l} / \mathrm{h})$.

Mice were ventilated using a special rodent ventilation system, which continuously recorded airway pressure, respiratory rate, and tidal volume. Dynamic elastance, resistance, and compliance were measured every $5 \mathrm{~min}$ using a forced oscillation technique (flexiVent; Scireq, Montreal, QC, Canada). Static compliance was recorded during the initial recruitment maneuver and at the end of the experiment after exsanguination.

After preparation, a recruitment maneuver was performed (increasing airway pressure to $27 \mathrm{cmH}_{2} \mathrm{O}$ ), and mice were ventilated for $4 \mathrm{~h}$ with the ventilator settings according to the study groups:

1. Low tidal volume (LTV): tidal volume of $8 \mathrm{ml} / \mathrm{kg}$, respiratory rate of $160 /$ min; deep inflation $\left(27 \mathrm{cmH}_{2} \mathrm{O}\right.$ for $1 \mathrm{~s}$ ) was performed every 5 min to avoid atelectasis.

2. High tidal volume (HTV): tidal volume of $34 \mathrm{ml} / \mathrm{kg}$, respiratory rate of $70 / \mathrm{min}$.

3. Non-ventilated (NV): ctrl mice, LTV ventilation was stopped after 10 min to generate baseline data on MV.

To avoid differences in $\mathrm{pH}$ value and partial arterial pressure of carbon dioxide $\left(\mathrm{paCO}_{2}\right)$ the dead space of the respirator tubing was adjusted in the HTV groups resulting in equal values in both groups.

Mean blood pressure, heart rate, and peripheral oxygen saturation (MouseOx; Starr Life Science Corp., Oakmont, PA, USA) were recorded every $10 \mathrm{~min}$ during the experiment. In all groups, mean arterial pressure remained stable during the experiment indicating that a potential influence of haemodynamic deterioration on the results can be excluded (Additional file 1: Figure S2).

Ninety minutes before the end of experiment, $1 \mathrm{mg}$ human serum albumin (HSA) was administered through the arterial catheter. After $240 \mathrm{~min}$ of $\mathrm{MV}, \mathrm{FiO}_{2}$ was increased to 1.0 for $10 \mathrm{~min}$. Five minutes before final exsanguination, heparin was administered through the arterial catheter. At termination of the experiment, mice were killed by exsanguination via the carotid artery catheter. Two LTV ctrl and one LTV antibiotic-treated (ATB) mice had to be excluded due to development of pneumothorax during ventilation. One LTV and two HTV antibiotic-treated mice, two HTV ctrl mice, one NV ctrl, and one NV antibiotic mouse had to be excluded due to technical issues during the experiment. One LTV antibiotic-treated mouse had to be euthanized during antibiotic treatment. The resulting number in each group were: $\mathrm{NV}$ ctrl and $\mathrm{NV}$ ATB $n=9$, LTV $\operatorname{ctrl} n=8$, LTV ATB $n=7$, HTV ctrl and HTV ATB $n=8$. For histological examination three mice were examined in each group. For the detailed numbers of animals per figure please refer to the figure legends.

\section{Blood gas analysis}

Blood samples were immediately analyzed using a blood gas analyzer (ABL 800; Radiometer, Copenhagen, Denmark) to determine partial pressure of arterial oxygen $\left(\mathrm{PaO}_{2}\right)$. The oxygenation index $(\mathrm{OI})$ was calculated as the product of mean airway pressure and the $\mathrm{FiO}_{2}$ divided by $\mathrm{PaO}_{2}$ as described previously [21].

\section{Differential blood count and plasma preparation}

Blood leukocytes and platelets were differentiated using a Scil Vet abc hematology analyzer (Scil animal care company $\mathrm{GmbH}$, Viernheim, Germany). Remaining blood was centrifuged $(12000 \times \mathrm{g}, 10 \mathrm{~min})$ and plasma stored at $-80^{\circ} \mathrm{C}$.

\section{Histopathologic analysis}

After exsanguination, the lungs were photographed. Subsequently, the lungs were carefully removed and fixed in formalin $\mathrm{pH} 7.0$ for $24-48 \mathrm{~h}$, embedded in paraffin and cut into $2-\mu \mathrm{m}$ sections. After routine dewaxing and dehydration, sections were stained with hematoxylin and eosin (H\&E) or Periodic acid-Schiff reaction (PAS). Organs were microscopically evaluated by two independent board-certified veterinary pathologists, blinded to the study groups. Due to red cast reduction of macro images, color auto-correction using ADOBE $^{\circ}$ PHOTOSHOP $^{\circ}$ CS5 Extended, Version 12.0.4 was performed.

\section{Bronchoalveolar lavage and lung processing}

The lungs were perfused with sterile cooled $1 \times$ PBS (Gibco; Thermo Fisher Scientific, Altham, MA, USA) via a catheter ligated in the pulmonary artery. Prior to bronchoalveolar lavage (BAL) of the left lungs, the right stem of the bronchus was ligated. Lavage was performed four times with $400 \mu \mathrm{l}$ PBS containing protease inhibitor (complete mini; MERCK KGaA, Darmstadt, Germany). BAL fluid (supernatant) and BAL cells (pellet) were separated by centrifugation at $300 \times \mathrm{g}$. BAL fluid was shock-frosted in liquid nitrogen and stored at $-80^{\circ} \mathrm{C}$ until further analysis. BAL cells were resuspended in staining buffer and stored at $4{ }^{\circ} \mathrm{C}$. The right lung lobes were minced, divided into three, two parts were shock-frosted in liquid nitrogen and stored at $-80{ }^{\circ} \mathrm{C}$ until further analysis. One part was used for lung leukocyte isolation.

\section{Isolation of lung leukocytes and flow cytometry}

For isolation of lung leukocytes, minced lung tissue was digested in RPMI medium supplemented with collagenase (MERCK KGaA) and DNAse (PanReack AppliChem $\mathrm{GmbH}$, Darmstadt, Germany) for $30 \mathrm{~min}$ at $37^{\circ} \mathrm{C}$. Single cell suspension was prepared by using $70-\mu \mathrm{m}$ cell strainers (BD, Heidelberg, Germany) and red blood cell lysis was performed. BAL and lung immune cells were differentiated by flow cytometry. Isolated BAL cells were blocked 
with anti-CD16/CD32 (BD) and stained with anti-CD11c (N418; ATCC), anti-CD11b (M1/70; eBioscience, Vienna, Austria), anti-F4/80 (BM8; eBioscience), anti-Ly6G (1A8; $\mathrm{BD})$, and anti-Ly6C (AL-21; BD) monoclonal antibodies (mAbs). The FL-1 channel was used to determine autofluorescence of cells. The gating strategy is shown in Additional file 1: Figure S3. Isolated lung cells were blocked with anti-CD16/CD32 (BD), surface stained with anti-CD4 (RM4-5; BD), anti-CD8 (53-6.7; eBioscience), anti CD3 (17A2; eBioscience), and gdTCR (GL-3; BD), fixed and permeabilized with FoxP3 / Transcription Factor Staining Buffer Set (eBioscience) and stained intranuclearly with anti-FoxP3 (FJK-16s; eBioscience) mAbs. All stained cells were acquired using a BD FACS Canto II and analyzed with BD FACSDiva and FlowJo software. For calculation of total cell numbers, CountBright Absolute Counting Beads (Thermo Fisher Scientific) were used.

\section{Lung permeability}

The HSA concentration was determined in BAL fluid (BALF) and plasma by ELISA (Bethyl, Biomol, Hamburg, Germany), and the HSA BALF/plasma ratio was calculated to assess the alveolar-capillary barrier permeability index as described previously [22-24].

\section{Cytokine protein measurements}

Prior to analysis, minced lung tissues were pre-treated with protein lysis buffer (BD). Cytokines were quantified from plasma and lung tissue samples by ProcartaPlex Custom Mix \& Match according to the manufacturer's instructions (eBioscience).

\section{mRNA isolation and expression analysis}

Minced lung tissue was homogenized with Gentle MACS M tubes (Miltenyi Biotec, Bergisch Gladbach, Germany) in TRIzol and RNA was extracted according to the manufacturer's instructions (Thermo Fisher Scientific). cDNA was transcribed by high capacity reverse transcription kit (Applied Biosystems, Life Technologies, Darmstadt, Germany). Quantitative PCR (qPCR) was performed on ABI 7300 using TaqMan gene expression assays (Applied Biosystems, Life Technologies). The qPCR conditions were as follows: denaturation in one cycle of $2 \mathrm{~min}$ at $50{ }^{\circ} \mathrm{C}$ and $10 \mathrm{~min}$ at $95{ }^{\circ} \mathrm{C}$, followed by 40 cycles of $15 \mathrm{~s}$ at $95{ }^{\circ} \mathrm{C}, 20 \mathrm{~s}$ at $60^{\circ} \mathrm{C}$, and $1 \mathrm{~min}$ at $72{ }^{\circ} \mathrm{C}$. Results were normalized to Gapdh levels and compared to the average expression of the target signals in the NV control mice as described previously $[21,25]$. Primer and probe sequences are provided in Additional file 1: Table S1.

\section{Molecular analysis of fecal microbiota}

Fecal pellets were collected directly before ventilation and stored at $-80{ }^{\circ} \mathrm{C}$ until measurement. DNA was extracted as described previously $[20,26,27]$. Bacteria, which are mainly found in the gut of mice were examined using qPCR with species-specific, genera-specific or group-specific 16S rRNA gene primers (Tib MolBiol, Berlin, Germany) as described previously [28]. Briefly, numbers of $16 \mathrm{~S}$ rRNA gene copies per nanogram DNA were assessed including total eubacterial load, Enterococcus spp., lactic acid bacteria, Bifidobacterium spp., Bacteroides/Prevortella spp., Clostridium coccoides group, Clostridium leptum group and mouse intestinal Bacteroides.

\section{Data analyses}

Data are expressed as mean with SD or boxplots depicting median, quartiles, and range excluding outliers (as shown as open circles) or as single values with median. For comparison between two groups the Mann-Whitney $U$ test was used. For grouped analyses, two-way analysis of variance (ANOVA) or two-way-repeated measures ANOVA/ Tukey's multiple comparison test was performed. $P$ values $<0.05$ were considered significant. Analyses were performed using GraphPad Prism 6 (San Diego, CA, USA).

\section{Results \\ Microbiota depletion prior to mechanical ventilation aggravated HTV ventilation-induced worsening of lung function}

To investigate the impact of antibiotic-treatment-related disruption of the microbiome on ventilator-induced lung injury we measured parameters of lung function. Ventilation of mice with HTV led to an increase in pulmonary dynamic elastance compared to LTV ventilation, which was significantly higher following microbiota depletion (Fig. 1a). In contrast, in both groups ventilated with LTV, pulmonary dynamic elastance remained unaffected throughout the experiment.

The static compliance at the beginning of the ventilation showed no difference within the groups (Fig. 1b), whereas the static compliance was reduced in microbiota-depleted HTV-ventilated mice, compared to control mice after $4 \mathrm{~h}$ of ventilation (Fig. 1c). These data indicate that microbiota depletion by antibiotic treatment prior to MV worsens VILI.

\section{Microbiota depletion prior to MV increased pulmonary permeability and OI in HTV-ventilated mice}

Since pulmonary hyperpermeability is the main underlying mechanism of edema formation and related worsening of lung function in acute lung injury, we measured pulmonary permeability. Microbiota depletion by antibacterial therapy prior to ventilation did not affect lung permeability in NV and LTV-ventilated mice. Non-treated 

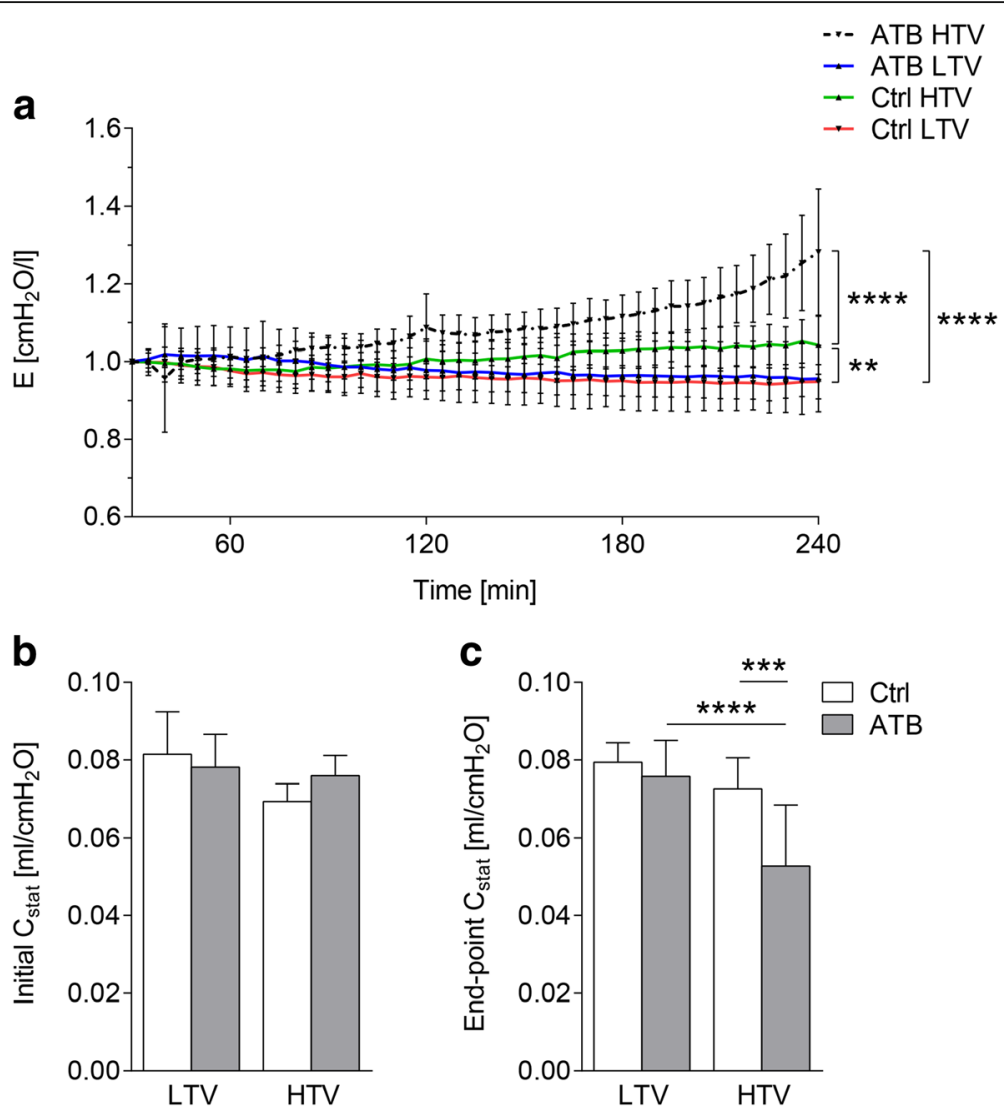

Fig. 1 Microbiota depletion prior to mechanical ventilation aggravated high tidal volume (HTV) ventilation-induced worsening of lung function. Mice received antibiotic broad-spectrum therapy (ATB). Control (Ctrl) mice did not receive antibiotic treatment. Ventilator-induced lung injury (VILI) was induced 3 days after completing antibiotic treatment protocol by (HTV) ventilation $(34 \mathrm{ml} / \mathrm{kg}$; positive end-expiratory pressure $=2$ $\mathrm{CmH}_{2} \mathrm{O}, 4 \mathrm{~h}$ ). Additional groups of mice were ventilated with low tidal volume (LTV). a Dynamic elastance (E) was measured in 5-min intervals during ventilation. Baseline was set to $30 \mathrm{~min}$ and values were normalized to baseline. $\mathbf{b}$-c Static compliance $\left(\mathrm{C}_{\text {stat }}\right)$ was measured at the start (b) and after $4 \mathrm{~h}$ of ventilation (c). Values are given as mean \pm SD (a) or mean and SD (b-c). In $\mathbf{a} n=11$ (LTV ctrl) or $n=7$ (HTV ctrl, HTV ATB) or $n=6$ (LTV ATB); in $\mathbf{b} n=11$ (LTV ctrl, HTV ctrl, HTV ATB) or $n=10$ (LTV ATB); $c n=11$ (HTV ctrl) or $n=10$ (LTV ctrl, LTV ATB, HTV ATB). Analysis was by two-way repeated measures analysis of variance (ANOVA)/Tukey's multiple comparison test (a) or by two-way ANOVA/Tukey's multiple comparison test $(\mathbf{b}-\mathbf{c}) .{ }^{* *} P<0.01,{ }^{* * *} P<0.001,{ }^{* * *} P<0.0001$

HTV mice had a trend towards increased permeability compared to non-treated NV and LTV mice. Under HTV ventilation, pulmonary vascular permeability was significantly increased in mice after receiving antibacterial therapy (Fig. 2a). In the NV and LTV groups, the OI was unchanged throughout the experiment, while HTV-ventilated mice had a higher oxygenation index compared to $\mathrm{NV}$ and LTV-ventilated mice (Fig. 2b). In microbiota-depleted mice, HVT ventilation increased the OI significantly.

\section{Microbiota depletion prior to MV worsened lung injury in HTV-ventilated mice}

The extent of ventilation correlates with lung tissue damage [21]. While ventilation with LTV did not lead to any macroscopic alteration of the lungs, HTV-ventilated mice had reddish discolored areas, which were more pronounced in mice receiving antibiotic therapy prior to mechanical ventilation (Fig. 3). No signs of acute lung injury were observed in naive mice (Additional file 1: Figure S4).

\section{Microbiota depletion prior to mechanical ventilation aggravated the inflammatory response in VILI}

To evaluate the effect of microbiota depletion on the inflammatory response to $\mathrm{MV}$, we measured protein and mRNA levels of key inflammatory mediators and assessed various innate and adaptive immune cell populations in the blood, lungs, and alveolar spaces. Mice receiving antibiotic therapy prior to HTV-ventilation had higher CXCL1/keratinocyte-derived chemokine (KC), and IL-6 protein levels in lung tissue, whereas protein levels in plasma from HTV-ventilated mice were not increased after microbiota depletion (Fig. 4a, b). Examination of gene regulation after antibacterial therapy revealed enhanced $I l 6$ mRNA expression in the lungs of HTV-ventilated mice that received antibiotic therapy prior to ventilation 

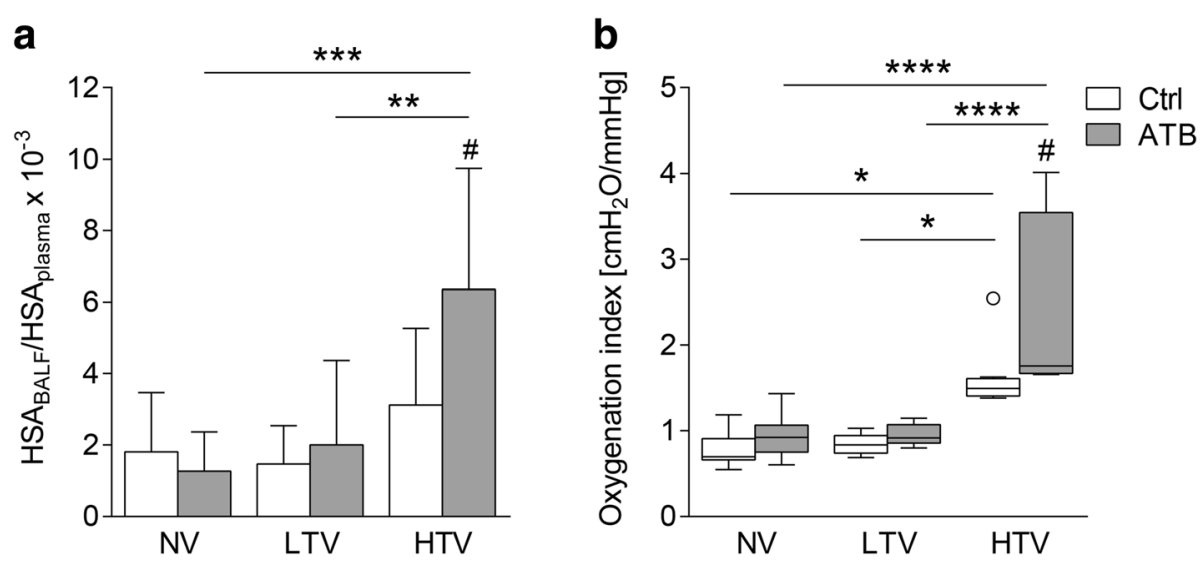

Fig. 2 Microbiota depletion prior to mechanical ventilation increased pulmonary permeability and oxygenation index in high tidal volume (HTV)-ventilated mice. Mice received antibiotic broad-spectrum therapy (ATB). Control (Ctrl) mice did not receive antibiotic treatment. Ventilatorinduced lung injury (VILI) was induced 3 days after completing antibiotic treatment protocol by (HTV) ventilation (34 ml/kg; positive endexpiratory pressure $=2 \mathrm{~cm} \mathrm{H} 2 \mathrm{O}, 4 \mathrm{~h}$ ). Additional groups of mice were ventilated with low tidal volume (LTV) or did not receive ventilation (NV). a Pulmonary barrier integrity index was calculated as ratio of human serum albumin (HSA) protein levels determined by ELISA in bronchoalveolar lavage fluid (BALF) and plasma. b Oxygenation index (OI) was calculated as the product of mean airway pressure and the fraction of inspired oxygen divided by the partial pressure of arterial oxygen. Values are given as mean and SD (a) or box plots depicting median, quartiles and range excluding outliers (open circles) (b). In a $n=8$ (NV ctrl, NV ATB, LTV ctrl, HTV ctrl, HTV ATB) or $n=6$ (LTV ATB); in b $n=9$ (NV ctrl) or $n=8$ (LTV ctrl, HTV ctrl, NV ATB, HTV ATB), or $n=6$ (LTV ATB), two-way analysis of variance/Tukey's multiple comparison test, "indicates difference in HTV ATB vs. HTV Ctrl, *as indicated, ${ }^{* / \#} P<0.05,{ }^{* *} P<0.01,{ }^{* * *} P<0.001,{ }^{* * * *} P<0.0001$

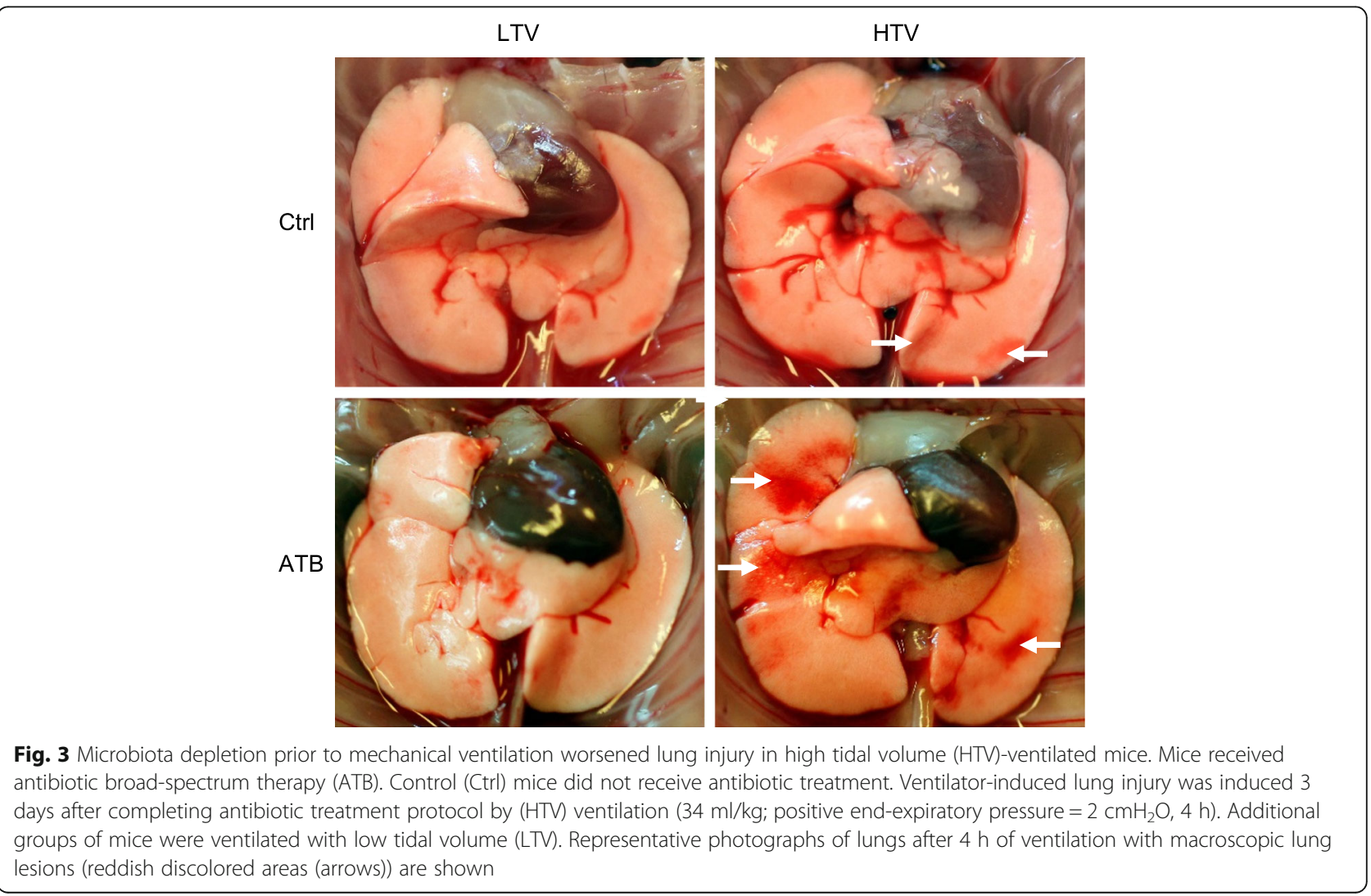



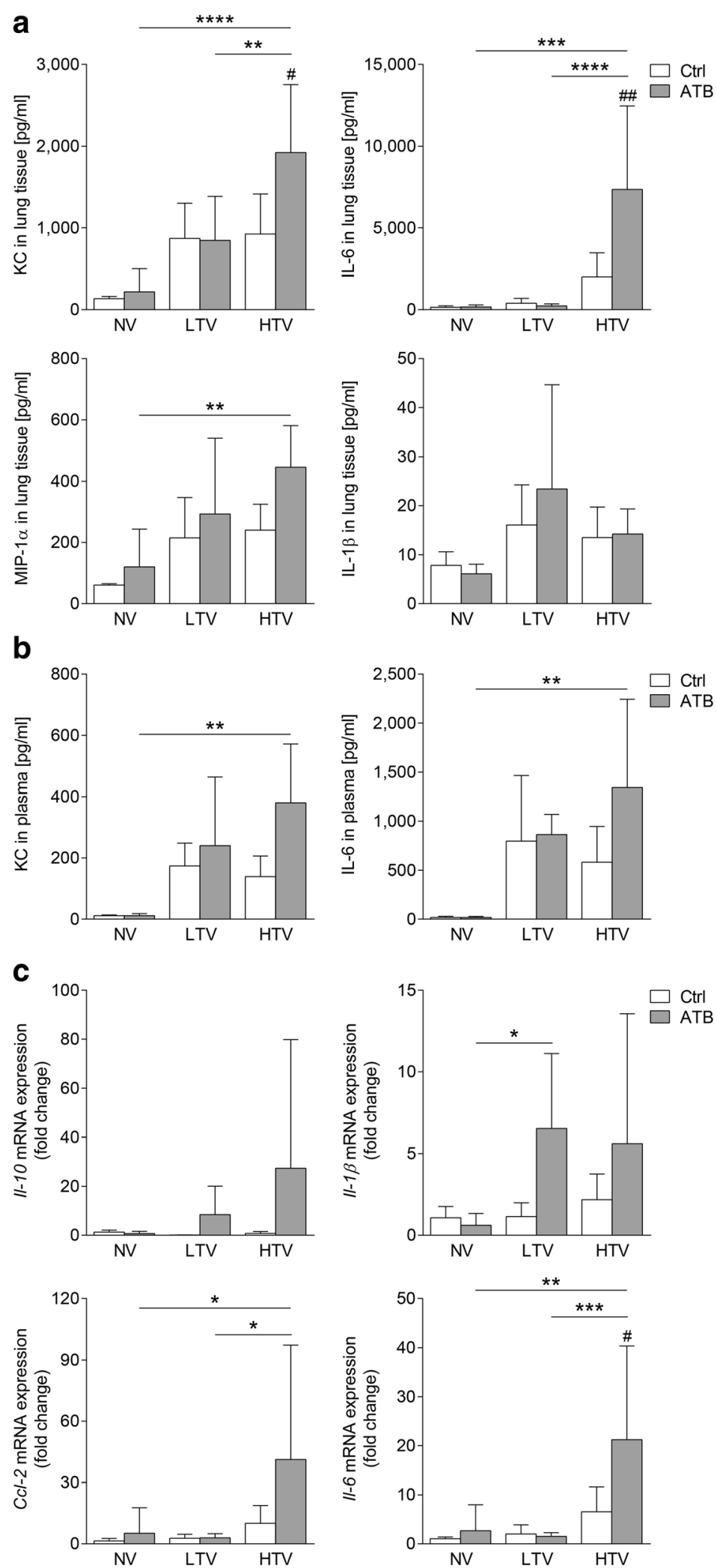

Fig. 4 (See legend on next page.) 


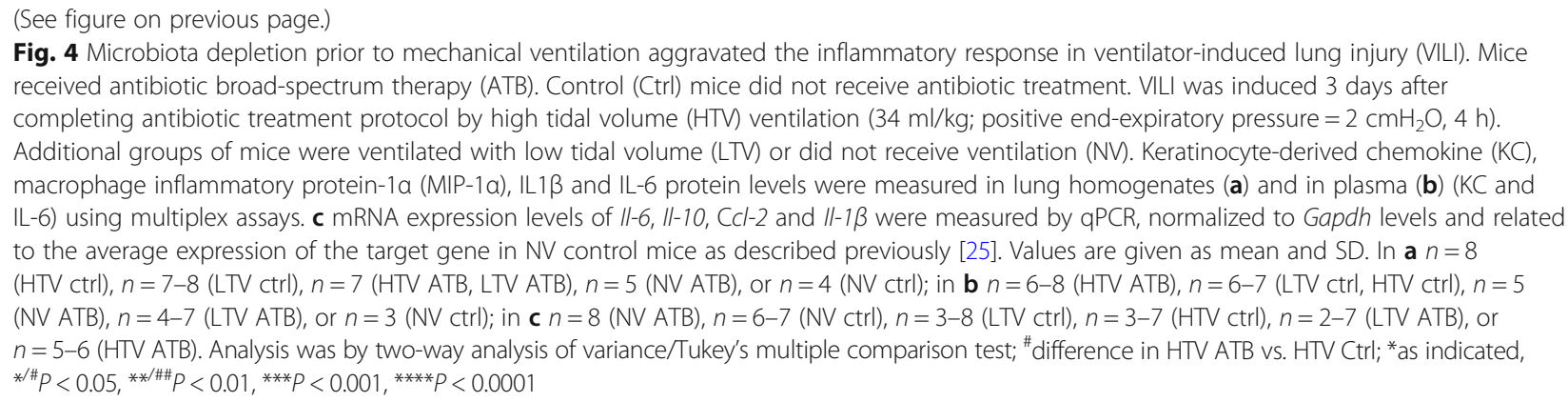

(Fig. 4c). Notably, despite increasing levels of inflammatory molecules, microbiota depletion prior to MV had no significant impact on recruitment of inflammatory cells (polymorphonuclear leukocytes (PMN) and inflammatory macrophages (iMs)) into the alveolar spaces and the lungs in HTV-ventilated mice. Likewise, further cellular populations (including CD4 T cells, CD8 T cells, regulatory T cell (Treg), $\gamma \delta \mathrm{T}$ cells, alveolar macrophages (alvMs), blood monocytes, blood granulocytes, platelets) remained unaffected by antibacterial treatment prior to ventilation (Fig. 5 and Additional file 1: Figure S5).

\section{Discussion}

In the current study we found that disruption of the microbiota by antibiotic therapy prior to mechanical ventilation (MV) increased the susceptibility to ventilator-induced lung injury (VILI). Mechanical ventilation is a life-saving intervention without an alternative for patients with respiratory failure, but it may aggravate or even induce VILI [29]. Further, mechanically ventilated critically ill patients are frequently exposed to antibiotic treatment (reviewed in [30]) or receive selective digestive decontamination (SDD) [31]. Antibiotics change the microbiota composition, which impacts the local and systemic inflammatory response towards various stimuli [32-36]. Taking this into account it is of great interest to determine the effect of antibiotic therapy and associated microbiota alteration on the development of VILI.

To investigate this interaction, we treated mice for 68 weeks with a broad-spectrum antibiotic regimen to generate mice with a virtually depleted gut microbiota. Using the described cocktail, we showed a significant decline in relevant bacterial species in the gut, but as part of the antibiotic applied is absorbed in the gut, the general microbiome of the animals is likely to be changed, which has to be considered in the interpretation of our results. It has been reported that treatment with antibiotics renders patients susceptible to pulmonary infections including multidrug-resistant pathogens [37, 38]. Recently, we have shown that antibiotic treatment lowers pulmonary IgA production and enhances susceptibility of mice towards $P$. aeruginosa [12]. However, the impact of the microbiota on the development of a hyperinflammatory sterile lung injury like VILI remains unclear. Using the described antibiotic cocktail including systemically effective antibiotics, we efficiently depleted the microbiota of the gut, but probably also of other organs including the lungs.

Prolonged antibiotic treatment prior to ventilation significantly aggravated VILI, as indicated by increased pulmonary permeability, decreased pulmonary compliance reflecting lung edema, and macroscopic signs of aggravated lung injury. An extensive proinflammatory response towards MV is a major driver of VILI, and alteration of the microbiota was reported to have a significant impact on the regulation of pulmonary inflammation $[39,40]$. We found elevated protein levels of KC and IL-6 in antibiotic-treated mice subjected to VILI, but did not detect any effect of microbiome depletion on the inflammatory response in non-ventilated mice. It remains unclear if the aggravated inflammatory response to VILI in antibiotic-treated mice may be the consequence of aggravated lung injury due to MV and associated inflammation or if the absence of an intact microbiome prior to VILI may have rendered the lung more reactive leading to an increased inflammatory response.

In this study, we implemented severely injurious ventilation in mice applying a tidal volume of $34 \mathrm{ml} / \mathrm{kg}$, which was much higher than the standard of lung-protective ventilation tidal volume of $6 \mathrm{ml} / \mathrm{kg}$ in humans with acute respiratory distress syndrome (ARDS). At first view, this might outrange the stress and strain applied during MV in patients with ARDS. However, functional residual lung capacity in ARDS is severely reduced, which is referred to as the "baby lung" in patients with ARDS [41]. Even with a tidal volume of $6 \mathrm{ml} / \mathrm{kg}$ it is unclear how much lung strain is produced during MV but available data show that lung stress and strain are significantly increased [42]. Further, the high grade of tissue inhomogeneity in lungs in ARDS, in which open, atelectatic, and collapsed but recruitable lung areas coexist, locally results in lung stress exceeding the measured airway pressure by far [43]. In the applied model, we used previously healthy lungs, sufficiently recruited at the beginning of MV. Therefore, the lungs are 

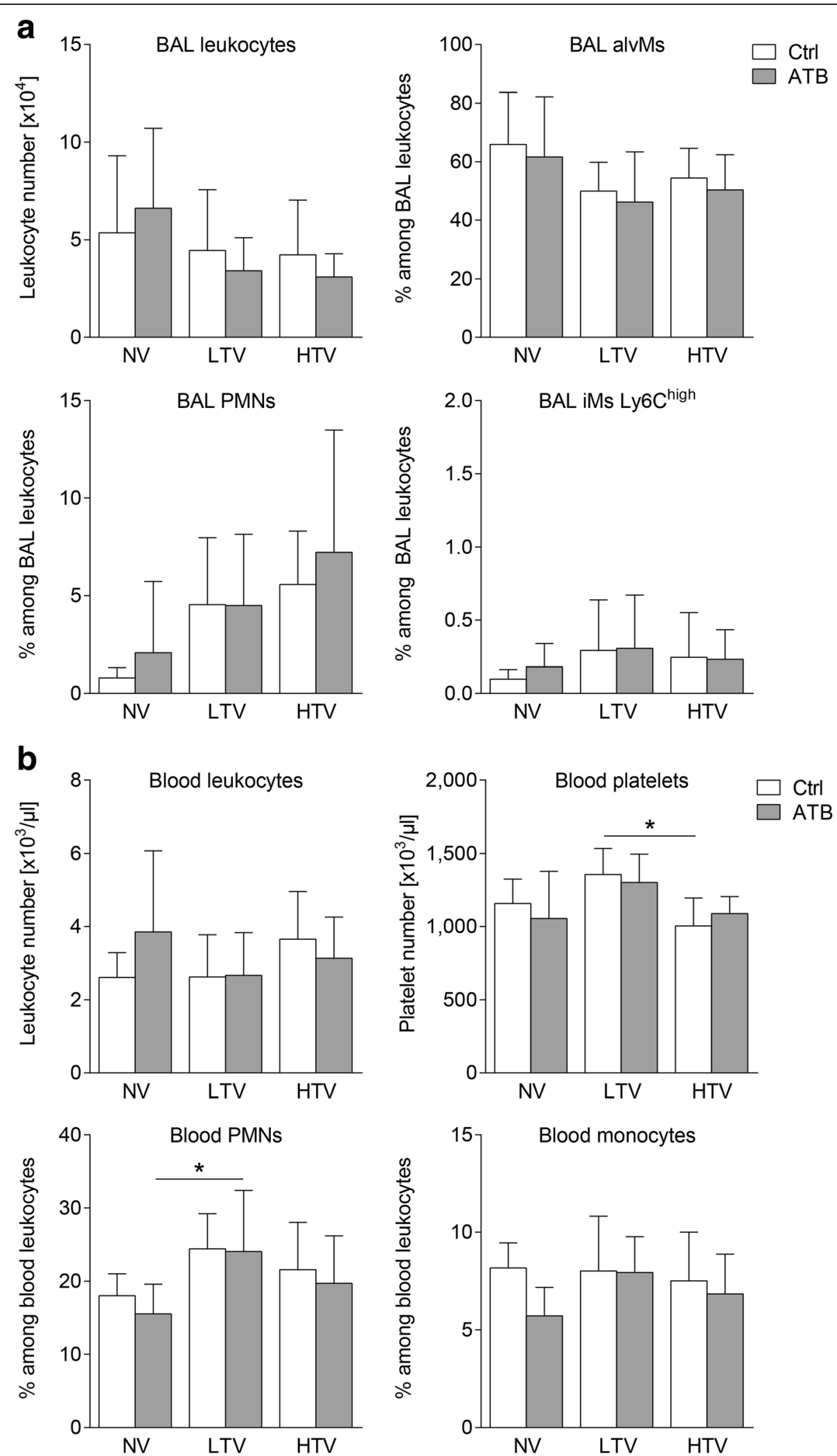

Fig. 5 (See legend on next page.) 
(See figure on previous page.)

Fig. 5 Microbiota depletion prior to mechanical ventilation had no impact on composition and recruitment of bronchoalveolar lavage (BAL) innate alveolar cells and blood leukocyte populations upon ventilation. Mice received antibiotic broad-spectrum therapy (ATB). Control (Ctrl) mice did not receive antibiotic treatment. Ventilator-induced lung injury was induced 3 days after completing the antibiotic treatment protocol by high tidal volume (HTV) ventilation ( $34 \mathrm{ml} / \mathrm{kg}$; positive end-expiratory pressure $=2 \mathrm{cmH}_{2} \mathrm{O}, 4 \mathrm{~h}$ ). Additional groups of mice were ventilated with low tidal volume (LTV) or did not receive ventilation (NV). a Numbers of BAL leukocytes and frequencies of alveolar macrophages (alvMs), polymorphonuclear cells (PMNs) and inflammatory macrophages (iMs) Ly6Chigh in BAL as quantified by flow cytometry. b Numbers of blood leukocytes and platelets and frequencies of PMNs (granulocytes minus eosinophils) and monocytes measured in EDTA-blood by Scil Vet abc hematology analyzer. Values are given as mean and SD. In a leukocyte numbers, $n=7$ (NV ctrl, NV ATB, LTV ctrl, HTV ATB), $n=6$ (HTV ctrl) or $n=3$ (LTV ATB); leukocyte frequencies, $n=9$ (NV ATB), $n=8-9$ (NV ctrl), $n=8$ (LTV ctrl, HTV ctrl, HTV ATB), or $n=6-7$ (LTV ATB); in $\mathbf{b} n=9$ (NV ctrl, NV ATB), $n=8$ (HTV ATB), or $n=7$ (LTV ctrl, LTV ATB, HTV ctrl). Analysis was by two-way analysis of variance/Tukey multiple comparison test, ${ }^{*} P<0.05$

lacking consolidations and relevant atelectatic lung regions that account for the reduced functional residual capacity resulting in elevated lung strain in patients with ARDS even under lung-protective ventilation. Further, in the recruited healthy lungs homogenously ventilated local lung stress is minimized. Therefore simulating "clinically relevant" lung stress and strain accruing in patients with ARDS requires an experimental approach that provokes significant lung stress/strain in healthy lungs with previously normal residual capacity and in the context of homogenously open and ventilated lung tissue. Moreover, the lung injury to be investigated has to be prevalent in a feasible timeframe. Taking all this into account, ventilation with $34 \mathrm{ml} / \mathrm{kg}$ in healthy mice is a reasonable experimental approach for our study meeting the American Thoracic Society (ATS) criteria for lung injury research in animal models [21].

The complex interaction between gut and lung is still not fully understood. One possible pathway encompasses altered communication between these two compartments over the "gut-lung axis" (reviewed in [44, 45]). For instance, the risk of developing airway diseases is increased after antibiotic-induced alterations in the gut microbiota in early childhood [46-48]. The intestinal microbiota might influence pulmonary immune responses by distributing bacterial metabolites via the bloodstream, which may have direct immunomodulatory effects $[14,49]$. One of these immunomodulating mediators might be short-chain fatty acids (SCFA) which result from digestion and converting of indigestible nutrients by the commensal bacteria and have been shown to have anti-inflammatory action (as reviewed by Marsland [14]). Zhang et al. showed that prophylactic administration of the SCFA sodium butyrate reduced lung injury after sepsis and attenuated lung lesions [50]. Reduced anti-inflammatory properties could be a possible explanation for the aggravated inflammatory response to VILI that we observed. However, further studies are warranted to dissect in the current context whether elevated cytokines mediate the aggravation of lung injury or result from ventilation-induced tissue injury leading e.g. to the release of proinflammatory DAMPs $[51,52]$.
The approach of using long-term broad-spectrum antibiotics is a well-established method to deplete the microbiome in mice with no reports of any remarkable toxic effect to the animals [20, 26-28]. Accordingly, histopathological analysis of naive lungs in microbiotadepleted mice in our study did not reveal any signs of pulmonary toxicity of the applied antibiotic regimen. To minimize a possible influence of circulating bacterial components arising after antibiotic lysis of bacteria, we stopped the antibiotic therapy 3 days prior to ventilation to "wash out" all possible remaining antibiotic substances or circulating bacterial metabolites. Taking this into account, an underlying toxic effect of the antibiotics on the lung tissue is very unlikely.

Nevertheless, as yet unknown effects of such antibiotic intervention might have influenced the results of this study. Studies using germ-free mice and mice recolonized after antibiotic treatment may offer further insights and allow to dissect if the microbiome itself or determine whether other potential antibiotic-related effects have affected the susceptibility to VILI. Thus, despite all limitations of an experimental animal model, we judge the complex model used in the present study to be suitable to examine the influence of the microbiota on the development of lung injury, best modeling the situation of ICU patients.

\section{Conclusions}

In summary, microbiota depletion by antibacterial therapy prior to MV enhanced inflammatory responses towards MV and rendered mice susceptible to the development of VILI. The findings highlight a potentially relevant interaction of the microbiome with the inflammatory response in lung injury.

\section{Additional file}

\footnotetext{
Additional file 1: Figure S1. Intestinal microbiota density declines after oral antibiotic treatment. Figure S2. Mean arterial pressure during mechanical ventilation. Figure S3. Exemplary flow cytometric gating strategy of innate immune cell populations in the alveolar spaces. Figure S4. Antibiotic therapy did not per se lead to lung injury as assessed histologically. Figure S5. Microbiota depletion prior to mechanical ventilation had no impact on composition and recruitment of innate and adaptive alveolar cells in the lungs. Table S1. Primers used for qPCR. (PDF $1720 \mathrm{~kb}$ )
} 


\section{Abbreviations}

ATB: Antibiotic-treated; alvMs: Alveolar macrophages; ANOVA: Analysis of variance; ARDS: Acute respiratory distress syndrome; BAL: Bronchoalveolar lavage; BALF: Bronchoalveolar lavage fluid; $C_{\text {stat: }}$ Static compliance; Ctrl: Control; E: Dynamic elastance; ELISA: Enzyme-linked immunosorbent assay; $\mathrm{FiO}_{2}$ : Inspiratory fraction of oxygen; $\mathrm{HSA}$ : Human serum albumin; HTV: High tidal volume; IL-1 $\beta$ : Interleukin-1 beta; IL-6: Interleukin-6; iMs: Inflammatory macrophages; KC: Keratinocyte-derived chemokine; LTV: Low tidal volume; mAbs: Monoclonal antibodies; MAP: Mean arterial pressure; MIP-1a: Macrophage inflammatory protein-1a; MV: Mechanical ventilation; NV: Non-ventilated; Ol: Oxygenation index; $\mathrm{PaCO}_{2}$ : Partial arteria pressure of carbon dioxide; $\mathrm{paO}_{2}$ : Partial arterial pressure of oxygen; PBS: Phosphate-buffered saline; PEEP: Positive end-expiratory pressure; PMNs: Polymorphonuclear leukocytes; qPCR: Real-time polymerase chain reaction; SCFA: Short-chain fatty acids; Treg: Regulatory T cells;

VILI: Ventilator-induced lung injury

\section{Acknowledgements}

We thank Gernot Reifenberger for measuring bacterial DNA from fecal samples and Ulrike Escher, Michaela Wattrodt, Alexandra Bittroff-Leben, Angela Linke, and Ulrike Behrendt for their excellent technical assistance. We also thank Drs Birgitt Gutbier and Katrin Reppe for managing in-laboratory animal facilities. Parts of this work are incorporated into the doctoral thesis of Mario Macrì.

\section{Funding}

This study was partly supported by grants from the German Research Foundation to HMR (SFB-TR84 C7), MW (SFB-TR84 C3, C6), NS (SFB-TR84 B1), BO (SFB-TR84 A1, A5), ADG (SFB-TR84 Z1 b), and MMH (SFB-TR84 A5) and by the German Federal Ministry of Education and Research (e:Med CAPSyS-FKZ 01ZX1304B and 01ZX1604B (to NS and MW)). The funding sources had no influence on study design or the publication.

\section{Availability of data and materials}

Data are available on request.

\section{Ethics approval}

All animal procedures were approved by local institutional (Charité Universitätsmedizin Berlin) and governmental (Landesamt für Gesundheit und Soziales (LaGeSo) Berlin) authorities.

\section{Authors' contributions}

MW and HMR planned and supervised the study and drafted the manuscript. SMW and MM planned and performed experiments, supervised the study, analyzed the data, and drafted the manuscript. GN planned, performed, and analyzed flow cytometry and contributed to writing the manuscript. KD, CG, and ADG performed histological examination and contributed to writing the manuscript. MMH performed microbiota depletion of the mice and critically revised the manuscript for important intellectual content. JL, FS, BK, BO, and NS were involved in the study design and participated in drafting the manuscript. All authors read and approved the final manuscript.

\section{Consent for publication}

Not applicable.

\section{Competing interests}

The authors declare that they have no competing interests.

\section{Publisher's Note}

Springer Nature remains neutral with regard to jurisdictional claims in published maps and institutional affiliations.

\section{Author details}

'Division of Pulmonary Inflammation, Charité - Universitätsmedizin Berlin, corporate member of Freie Universität Berlin, Humboldt-Universität zu Berlin, and Berlin Institute of Health, Berlin, Germany. ${ }^{2}$ Department of Veterinary Pathology, Freie Universität Berlin, Berlin, Germany. ${ }^{3}$ Institute for Microbiology and Infection Immunology, Charité - Universitätsmedizin Berlin, corporate member of Freie Universität Berlin, Humboldt-Universität zu Berlin, and Berlin Institute of Health, Berlin, Germany. ${ }^{4}$ Department of Nutritional Toxicology, Institute of Nutritional Science, University of Potsdam, Nuthetal,
Germany. ${ }^{5}$ Department of Molecular Biology, University of Duisburg-Essen, Essen, Germany. ${ }^{6}$ Department of Infectious Diseases and Pulmonary Medicine, Charité - Universitätsmedizin Berlin, corporate member of Freie Universität Berlin, Humboldt-Universität zu Berlin, and Berlin Institute of Health, Charitéplatz 1, 10117 Berlin, Germany. Present address: Scuola di specializzazione in Anestesia, Rianimazione e Terapia Intensiva, Università degli Studi di Milano, Milan, Italy. ${ }^{8}$ Present address: Institute of Animal Pathology, Department of Infectious Diseases and Pathobiology, Vetsuisse Faculty, University of Bern, Bern, Switzerland.

Received: 9 July 2018 Accepted: 26 September 2018 Published online: 29 October 2018

\section{References}

1. The Acute Respiratory Distress Syndrome Network, Brower RG, Matthay MA, Morris A, Schoenfeld D, Thompson BT, Wheeler A. Ventilation with lower tidal volumes as compared with traditional tidal volumes for acute lung injury and the acute respiratory distress syndrome. N Engl J Med. 2000;342:1301-8.

2. Dreyfuss D, Saumon G. Ventilator-induced lung injury: lessons from experimental studies. Am J Respir Crit Care Med. 1998;157:294-323.

3. Ranieri VM, Giunta F, Suter PM, Slutsky AS. Mechanical ventilation as a mediator of multisystem organ failure in acute respiratory distress syndrome. JAMA. 2000;284:43-4.

4. Ranieri VM, Suter PM, Tortorella C, De Tullio R, Dayer JM, Brienza A, Bruno F, Slutsky AS. Effect of mechanical ventilation on inflammatory mediators in patients with acute respiratory distress syndrome: a randomized controlled trial. JAMA. 1999;282:54-61.

5. Zarb P, Coignard B, Griskeviciene J, Muller A, Vankerckhoven V, Weist K, Goossens MM, Vaerenberg S, Hopkins S, Catry B, Monnet DL, Goossens H, Suetens $C$, National Contact Points for the ECDC pilot point prevalence survey Collective, Hospital Contact Points for the ECDC pilot point prevalence survey Collective. The European Centre for Disease Prevention and Control (ECDC) pilot point prevalence survey of healthcare-associated infections and antimicrobial use. Euro Surveill. 2012;17(46). https://doi.org/10.2807/ese.17.46.20316-en.

6. Lederberg J, McCray AT. 'Ome sweet 'omics-a genealogical treasury of words. Scientist. 2001;15 Available from: https://www.the-scientist.com/ commentary/ome-sweet-omics\%2D\%2D-a-genealogical-treasury-of-words54889. Accessed 06 July 2018.

7. The NIH HMP Working Group, Peterson J, Garges S, Giovanni M, Mclnnes P, Wang L, Schloss JA, Bonazzi V, McEwen JE, Wetterstrand KA, et al. The NIH Human Microbiome Project. Genome Res. 2009;19:2317-23.

8. Samuelson DR, Welsh DA, Shellito JE. Regulation of lung immunity and host defense by the intestinal microbiota. Front Microbiol. 2015;6:1085.

9. Souza DG, Vieira AT, Soares AC, Pinho V, Nicoli JR, Vieira LQ, Teixeira MM. The essential role of the intestinal microbiota in facilitating acute inflammatory responses. J Immunol. 2004;173:4137-46.

10. Hand TW, Vujkovic-Cvijin I, Ridaura VK, Belkaid Y. linking the microbiota, chronic disease, and the immune system. Trends Endocrinol Metab. 2016;27:831-43.

11. Hooper LV, Littman DR, Macpherson AJ. Interactions between the microbiota and the immune system. Science. 2012;336:1268-73.

12. Robak OH, Heimesaat MM, Kruglov AA, Prepens S, Ninnemann J, Gutbier B, Reppe K, Hochrein H, Suter M, Kirschning CJ, et al. Antibiotic treatmentinduced secondary IgA deficiency enhances susceptibility to Pseudomonas aeruginosa pneumonia. J Clin Invest. 2018;128(8):3535-45. https://doi.org/10. 1172/JC197065. Epub 2018 Jul 16.

13. Schuijt TJ, Lankelma JM, Scicluna BP, de Sousa e Melo F, Roelofs JJ, de Boer JD, Hoogendijk AJ, de Beer R, de Vos A, Belzer C, et al. The gut microbiota plays a protective role in the host defence against pneumococcal pneumonia. Gut. 2016:65:575-83.

14. Marsland BJ, Trompette A, Gollwitzer ES. The gut-lung axis in respiratory disease. Ann Am Thorac Soc. 2015;12(Suppl 2):S150-6.

15. Tedelind S, Westberg F, Kjerrulf M, Vidal A. Anti-inflammatory properties of the short-chain fatty acids acetate and propionate: a study with relevance to inflammatory bowel disease. World J Gastroenterol. 2007;13:2826-32.

16. Clarke TB, Davis KM, Lysenko ES, Zhou AY, Yu Y, Weiser JN. Recognition of peptidoglycan from the microbiota by Nod1 enhances systemic innate immunity. Nat Med. 2010;16:228-31.

17. Wienhold SM, Macri M, Nouailles-Kursar G, Opitz B, Dietert K, Gruber AD, Suttorp N, Heimesaat M, Witzenrath M, Müller-Redetzky HC. Disruption of the gut microbiome augments the development of ventilator-induced lung injury in mice. Pneumologie. 2017;71:S1-S125. 
18. Wienhold SM, Macri M, Nouailles G, Opitz B, Dietert K, Gruber AD, Suttorp N, Müller-Redetzky HC, Witzenrath M, Heimesaat MM. Ventilator-induced lung injury is aggravated by intestinal microbiome disruption in mice. Eur Respir J. 2017:50(Suppl 61):PA350.

19. Wienhold SM, Macri M, Nouailles-Kursar G, Opitz B, Dietert K, Gruber AD, Suttorp N, Heimesaat MM, Witzenrath M, Müller-Redetzky HC. Disruption of the gut microbiome augments development of ventilator-induced lung injury in mice. Am J Respir Crit Care Med. 2017;195:A2941.

20. Heimesaat MM, Bereswill S, Fischer A, Fuchs D, Struck D, Niebergall J, Jahn HK, Dunay IR, Moter A, Gescher DM, et al. Gram-negative bacteria aggravate murine small intestinal Th1-type immunopathology following oral infection with Toxoplasma gondii. J Immunol. 2006;177:8785-95

21. Müller-Redetzky HC, Felten M, Hellwig K, Wienhold SM, Naujoks J, Opitz B, Kershaw O, Gruber AD, Suttorp N, Witzenrath M. Increasing the inspiratory time and I:E ratio during mechanical ventilation aggravates ventilatorinduced lung injury in mice. Crit Care. 2015;19:23.

22. Seybold J, Thomas D, Witzenrath M, Boral S, Hocke AC, Bürger A, Hatzelmann A, Tenor $H$, Schudt C, Krüll M, et al. Tumor necrosis factoralpha-dependent expression of phosphodiesterase 2: role in endothelial hyperpermeability. Blood. 2005;105:3569-76.

23. Witzenrath M, Gutbier B, Hocke AC, Schmeck B, Hippenstiel S, Berger K, Mitchell TJ, de los Toyos JR, Rosseau S, Suttorp N, et al. Role of pneumolysin for the development of acute lung injury in pneumococcal pneumonia. Crit Care Med. 2006;34:1947-54.

24. Müller HC, Hellwig K, Rosseau S, Tschernig T, Schmiedl A, Gutbier B, Schmeck B, Hippenstiel S, Peters H, Morawietz L, et al. Simvastatin attenuates ventilator-induced lung injury in mice. Crit Care. 2010;14:R143.

25. Müller-Redetzky HC, Will D, Hellwig K, Kummer W, Tschernig T, Pfeil U, Paddenberg R, Menger MD, Kershaw O, Gruber AD, et al. Mechanical ventilation drives pneumococcal pneumonia into lung injury and sepsis in mice: protection by adrenomedullin. Crit Care. 2014;18:R73.

26. Bereswill S, Kühl AA, Alutis M, Fischer A, Möhle L, Struck D, Liesenfeld O, Göbel UB, Dunay IR, Heimesaat MM. The impact of Toll-like-receptor-9 on intestinal microbiota composition and extra-intestinal sequelae in experimental Toxoplasma gondii induced ileitis. Gut Pathog. 2014;6:19.

27. Heimesaat MM, Reifenberger G, Vicena V, Illes A, Horvath G, Tamas A, Fulop $\mathrm{BD}$, Bereswill S, Reglodi D. Intestinal microbiota changes in mice lacking pituitary adenylate cyclase activating polypeptide (PACAP) - bifidobacteria make the difference. Eur J Microbiol Immunol (Bp). 2017;7:187-99.

28. Bereswill S, Fischer A, Plickert R, Haag LM, Otto B, Kühl AA, Dasti JI, Dashti Jl, Zautner AE, Muñoz M, et al. Novel murine infection models provide deep insights into the "ménage à trois" of Campylobacter jejuni, microbiota and host innate immunity. PLoS One. 2011;6:e20953.

29. Verbrugge SJ, Lachmann B, Kesecioglu J. Lung protective ventilatory strategies in acute lung injury and acute respiratory distress syndrome: from experimental findings to clinical application. Clin Physiol Funct Imaging. 2007;27:67-90

30. Vincent JL, Bassetti M, François B, Karam G, Chastre J, Torres A, Roberts JA, Taccone FS, Rello J, Calandra T, et al. Advances in antibiotic therapy in the critically ill. Crit Care. 2016;20:133.

31. van der Waaij D, Manson WL, Arends JP, de Vries-Hospers HG. Clinical use of selective decontamination: the concept. Intensive Care Med. 1990;16(Suppl 3):S212-6.

32. Prakash A, Sundar SV, Zhu YG, Tran A, Lee JW, Lowell C, Hellman J. Lung ischemia-reperfusion is a sterile inflammatory process influenced by commensal microbiota in mice. Shock. 2015;44:272-9.

33. Cebra JJ. Influences of microbiota on intestinal immune system development. Am J Clin Nutr. 1999;69:1046S-51S.

34. Hall JA, Bouladoux N, Sun CM, Wohlfert EA, Blank RB, Zhu Q, Grigg ME, Berzofsky JA, Belkaid Y. Commensal DNA limits regulatory T cell conversion and is a natural adjuvant of intestinal immune responses. Immunity. 2008;29:637-49.

35. Ivanov II, Atarashi K, Manel N, Brodie EL, Shima T, Karaoz U, Wei D, Goldfarb KC, Santee CA, Lynch SV, et al. Induction of intestinal Th17 cells by segmented filamentous bacteria. Cell. 2009;139:485-98.

36. Mazmanian SK, Liu CH, Tzianabos AO, Kasper DL. An immunomodulatory molecule of symbiotic bacteria directs maturation of the host immune system. Cell. 2005;122:107-18.

37. Metersky ML, Frei CR, Mortensen EM. Predictors of Pseudomonas and methicillin-resistant Staphylococcus aureus in hospitalized patients with healthcare-associated pneumonia. Respirology. 2016;21:157-63.
38. Shindo $Y$, Ito $R$, Kobayashi $D$, Ando M, Ichikawa M, Shiraki A, Goto Y, Fukui $Y$, Iwaki M, Okumura J, et al. Risk factors for drug-resistant pathogens in community-acquired and healthcare-associated pneumonia. Am J Respir Crit Care Med. 2013;188:985-95.

39. Shukla SD, Budden KF, Neal R, Hansbro PM. Microbiome effects on immunity, health and disease in the lung. Clin Transl Immunol. 2017;6:e133.

40. Belkaid Y, Hand TW. Role of the microbiota in immunity and inflammation. Cell. 2014;157:121-41.

41. Gattinoni L, Pesenti A. The concept of "baby lung". Intensive Care Med. 2005;31:776-84.

42. Gattinoni L, Carlesso E, Caironi P. Stress and strain within the lung. Curr Opin Crit Care. 2012;18:42-7.

43. Chiumello D, Carlesso E, Cadringher P, Caironi P, Valenza F, Polli F, Tallarini F, Cozzi P, Cressoni M, Colombo A, et al. Lung stress and strain during mechanical ventilation for acute respiratory distress syndrome. Am J Respir Crit Care Med. 2008;178:346-55.

44. He Y, Wen Q, Yao F, Xu D, Huang Y, Wang J. Gut-lung axis: the microbial contributions and clinical implications. Crit Rev Microbiol. 2017;43:81-95.

45. Wu B, Segal L. Lung microbiota and its impact on the mucosal immune phenotype. Microbiol Spectr. 2017;5(3). https://doi.org/10.1128/microbiolspec. BAD-0005-2016.

46. Noverr MC, Falkowski NR, McDonald RA, McKenzie AN, Huffnagle GB. Development of allergic airway disease in mice following antibiotic therapy and fungal microbiota increase: role of host genetics, antigen, and interleukin-13. Infect Immun. 2005;73:30-8.

47. Russell SL, Gold MJ, Hartmann M, Willing BP, Thorson L, Wlodarska M, Gill N, Blanchet MR, Mohn WW, McNagny KM, et al. Early life antibiotic-driven changes in microbiota enhance susceptibility to allergic asthma. EMBO Rep. 2012;13:440-7.

48. Stokholm J, Blaser MJ, Thorsen J, Rasmussen MA, Waage J, Vinding RK, Schoos AM, Kunøe A, Fink NR, Chawes BL, et al. Maturation of the gut microbiome and risk of asthma in childhood. Nat Commun. 2018;9:141.

49. Cummings JH, Pomare EW, Branch WJ, Naylor CP, Macfarlane GT. Short chain fatty acids in human large intestine, portal, hepatic and venous blood. Gut. 1987;28:1221-7.

50. Zhang L, Jin S, Wang C, Jiang R, Wan J. Histone deacetylase inhibitors attenuate acute lung injury during cecal ligation and puncture-induced polymicrobial sepsis. World J Surg. 2010;34:1676-83.

51. Held HD, Boettcher S, Hamann L, Uhlig S. Ventilation-induced chemokine and cytokine release is associated with activation of nuclear factor-kappaB and is blocked by steroids. Am J Respir Crit Care Med. 2001;163:711-6.

52. Kuipers MT, van der Poll T, Schultz MJ, Wieland CW. Bench-to-bedside review: damage-associated molecular patterns in the onset of ventilatorinduced lung injury. Crit Care. 2011;15:235.
Ready to submit your research? Choose BMC and benefit from:
- fast, convenient online submission
- thorough peer review by experienced researchers in your field
- rapid publication on acceptance
- support for research data, including large and complex data types
- gold Open Access which fosters wider collaboration and increased citations
- maximum visibility for your research: over $100 \mathrm{M}$ website views per year
At BMC, research is always in progress.
Learn more biomedcentral.com/submissions 